\title{
A Novel Disease Entity in Search of Its Own Identity - Takotsubo Syndrome. Is It Really "Cardiomyopathy"? -
}

\author{
Yoshinori L. Doi, MD, PhD; Toru Kubo, MD, PhD; Hiroaki Kitaoka, MD, PhD
}

\begin{abstract}
Background: The term "takotsubo cardiomyopathy" is commonly used in clinical practice. However, there is conceptual problem with the term "cardiomyopathy" in this context because "cardiomyopathy" implies a primary and chronic myocardial disease of unknown etiology. In this study we reviewed the literature related to takotsubo cardiomyopathy to investigate whether it is appropriate to use the term "cardiomyopathy" for this condition.
\end{abstract}

\begin{abstract}
Methods and Results: A literature review revealed that this condition was originally described in 1990 in Japan as postischemic myocardial stunning with unique left ventricular apical ballooning and that it gradually gained global attention thereafter. Subsequently, the term "takotsubo cardiomyopathy" was introduced to describe this heart failure phenotype. However, this term has been called into question because several recent studies investigating the mechanism underlying this condition have provided evidence of myocardial ischemia possibly due to microvascular dysfunction. The term "takotsubo syndrome" was suggested to describe this microvascular acute coronary syndrome, which is in agreement with the original description of the condition as myocardial stunning following acute myocardial ischemia.
\end{abstract}

Conclusions: Based on the accumulating evidence of acute myocardial ischemia due to microvascular dysfunction as the mechanism underlying this condition, in addition to the fact that the term "cardiomyopathy" literally implies a primary and chronic myocardial disease, it is advisable that the term "takotsubo syndrome" is used until the etiology and underlying mechanism of this condition are fully clarified.

Key Words: Conceptual confusion; Microvascular dysfunction; Myocardial ischemia; Takotsubo cardiomyopathy; Takotsubo syndrome

${ }^{66} \mathrm{~T}$ akotsubo syndrome" is a novel disease entity first described by Japanese cardiologists in 1990 in 3 patients ( 2 women and 1 man) originally as stunned myocardium with unique end-systolic apical ballooning of the left ventricle secondary to multivessel coronary spasms. ${ }^{1}$ The term "tako-tsubo" was used to describe this unusual apical ballooning of the left ventricle (Figure) because it resembled the shape of a Japanese fisherman's octopus (tako) trap pot (tsubo) with a round bottom and narrow neck (Figure). Over the next decade, this novel condition was gradually recognized in Japan as the number of case presentations of patients with similar conditions started to accumulate.

In 2001, a group of Japanese investigators reported the clinical features of this condition in a substantial number of patients. ${ }^{2}$ The authors of that paper analyzed 88 patients, predominantly women, who fulfilled the criteria of transient left ventricular apical ballooning, no significant angiographic coronary stenosis, and "no known cardio- myopathies", and reported this condition as a novel heart syndrome with transient left ventricular apical ballooning, emphasizing the unique left ventricular morphology. ${ }^{2}$ Consequently, this condition caught the attention of the scientific and clinical cardiology communities and gradually gained global recognition. The term "takotsubo cardiomyopathy" was subsequently introduced to describe this condition. The term "cardiomyopathy" was used to indicate that this condition is a heart failure phenotype with cardiac dysfunction, but obviously not to suggest that it is primary myocardial disease.

More recently, the term "takotsubo cardiomyopathy" has been called into question because of the clinical presentation of this condition, with acute and transient left ventricular systolic dysfunction together with transient changes in the electrocardiogram (Figure) and cardiac biomarkers, such as troponins, and the term "takotsubo syndrome" was proposed instead..$^{3-5}$ Several recent studies investigating the mechanism underlying this condition also

Received June 8, 2020; accepted June 9, 2020; J-STAGE Advance Publication released online July 15, 2020 Time for primary review: 1 day

Cardiomyopathy Institute, Chikamori Hospital, Kochi (Y.L.D.); Department of Cardiology and Aging Science, Kochi Medical School, Nankoku (Y.L.D., T.K., H.K.), Japan

H.K. is a member of Circulation Reports' Editorial Team.

Mailing address: Yoshinori Doi, MD, PhD, Cardiomyopathy Institute, Chikamori Hospital, 1-1-16 Ohkawasuji, Kochi 780-8522, Japan. E-mail: ydoi@chikamori.com

All rights are reserved to the Japanese Circulation Society. For permissions, please e-mail: cr@j-circ.or.jp

ISSN-2434-0790 


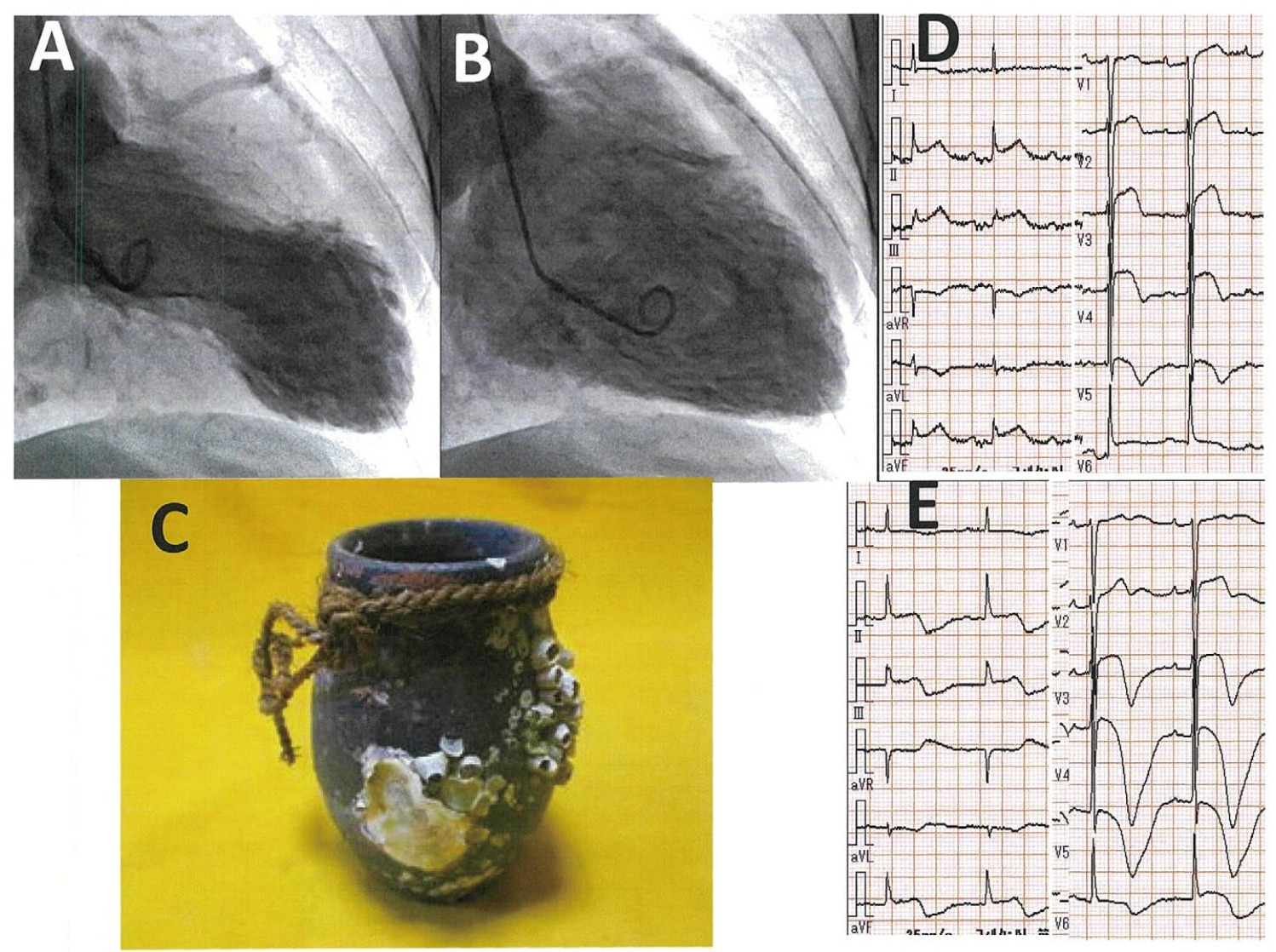

Figure. (A) Left ventriculogram at end-systole showing unique apical ballooning in a patient with Takotsubo syndrome. (B) Left ventriculogram at end-diastole in the same patient. (C) A Japanese fisherman's octopus (tako) trap pot (tsubo). (D) Electrocardiogram showing ST segment elevation in Leads II, III, aVF and V2-5 at the onset of Takotsubo syndrome. (E) The electrocardiogram at a few days later, showing T wave inversion associated with QT prolongation in the same leads.

provided evidence of myocardial ischemia possibly due to microvascular dusfunction. ${ }^{\mathbf{6}-10}$ This mechanism seems to involve cardiac sympathetic hyperactivity with increased circulating catecholamines, which induce coronary microvascular constriction together with endothelial dysfunction. It was therefore postulated that takotsubo syndrome can be defined as a microvascular acute coronary syndrome. ${ }^{4}$

Interestingly, this new definition of takotsubo syndrome is in agreement with the original description of the condition as postischemic myocardial stunning following acute myocardial ischemia. In this context of microvascular dysfunction, the emerging concept of open-artery ischemia, namely myocardial infarction with non-obstructive coronary arteries (MINOCA), predominantly seen in women, ${ }^{\mathbf{8}, 11,12}$ is of great interest in relation to the etiology of takotsubo syndrome. It appears that both conditions at least partly share a common mechanistic pathway, and it may be possible that these conditions eventually fall into the same disease entity group with somewhat different phenotypes.

There is also a conceptual problem with the term "cardiomyopathy". From the stand point of myocardial disease, Brigden was the among the first to use the term "cardiomyopathy", 13 followed by Goodwin et al, who first clinically defined cardiomyopathy as a disorder of heart muscle of unknown etiology. ${ }^{\mathbf{1 4}, 15}$ This concept was approved in 1980 by the joint task force of the World Health Organization and International Society and Federation of Cardiology (WHO/ISFC), ${ }^{\mathbf{1 6}}$ and was then revised in 1995 as a disease of the myocardium associated with cardiac dysfunction. ${ }^{17}$ Updated definitions of cardiomyopathy from the American Heart Association ${ }^{\mathbf{1 8}}$ and the European Society of Cardiology ${ }^{19}$ are available, and these are basically revisions of the 1995 WHO/ISFC classification. Therefore, the term "cardiomyopathy" literally implies a disease of the heart muscle and is applied to a primary heart muscle disorder of genetic or unknown etiology.

Conversely, the term "cardiomyopathy" has been used in a much broader sense, particularly in the US, to describe the heart failure phenotype with ventricular dysfunction, regardless of etiology. The term "ischemic cardiomyopathy", which is left ventricular dysfunction secondary to myocardial infarction, is one such example. Other examples may include diabetic cardiomyopathy and tachycardia-induced cardiomyopathy. Obviously, these conditions are not primary heart muscle disorders.

These conceptual differences in the term "cardiomyopathy" are problematic and sometimes misleading. They have brought about confusion in the pathophysiological understanding of takotsubo syndrome. Because of the term "cardiomyopathy", some have classified this condition as 
a myocardial disease, whereas others have simply considered it to be a heart failure phenotype with a unique ventricular dysfunction unrelated to myocardial disease. In order to avoid such conceptual confusion, it seems advisable not to use the term "cardiomyopathy" to describe this condition.

Because takotsubo syndrome is characterized by sudden onset, transient, and often reversible left ventricular dysfunction that is usually preceded by emotional and/or physical triggers, it seems appropriate to understand it as a condition that is different to chronic and usually progressive myocardial disease. It is our opinion that the clinical presentation of this condition indeed fits the concept of postischemic myocardial stunning in acute coronary syndrome as originally suggested 30 years ago. The results of several recent studies ${ }^{7-9}$ indicating myocardial ischemia as the etiology of the condition, probably secondary to microvascular dysfunction, also support our contention. At present, we believe that it is better to use the term "takotsubo syndrome" until the etiology and mechanism underlying this condition are fully clarified.

\section{Sources of Funding}

This study did not receive any specific funding.

\section{Disclosures}

H.K. is a member of Circulation Reports' Editorial Team. The remaining authors declare no conflicts of interest.

\section{IRB Information}

The present study was approved by the Ethics Committee of Chikamori Hospital (Reference no. 355).

\section{References}

1. Sato H, Tateishi H, Uchida T, Dote K, Ishihara M. Stunned myocardium with a unique tsubo-like left ventriculographic morphology due to multivessel coronary spasm. In: Kodama K, Haze K, Hori M, editors. Clinical aspect of myocardial injury: From ischemia to heart failure. Tokyo: Kagakuhyoronsha Publishing, 1990; 56-64 (in Japanese).

2. Tsuchihashi K, Ueshima K, Uchida T, Oh-mura N, Kimura K, Owa M, et al. Transient left ventricular apical ballooning without coronary artery stenosis: A novel heart syndrome mimicking acute myocardial infarction. J Am Coll Cardiol 2001; 38: 11-18.

3. Lüscher TF, Templin C. Is takotsubo syndrome a microvascular acute coronary syndrome?: Towards a new definition. Eur Heart
$J$ 2016; 37: 2816-2820

4. Ghadri JR, Wittstein IS, Prasad A, Sharkey S, Dote K, Akashi $\mathrm{YJ}$, et al. International expert consensus document on takotsubo syndrome (Part I): Clinical characteristics, diagnostic criteria, and pathophysiology. Eur Heart J 2018; 39: 2032-2046.

5. Ghadri JR, Wittstein IS, Prasad A, Sharkey S, Dote K, Akashi YJ, et al. International expert consensus document on takotsubo syndrome (Part II): Diagnostic workup, outcome, and management. Eur Heart J 2018; 39: 2047-2062.

6. Wittstein IS, Thiemann DR, Lima JAC, Baughman KL, Schulman SP, Gerstenblith G, et al. Neurohormonal features of myocardial stunning due to sudden emotional stress. $N$ Engl $J$ Med 2005; 352: 539-548.

7. Galiuto L, De Caterina AR, Porfidia A, Paraggio L, Barchetta $\mathrm{S}$, Locorotondo $\mathrm{G}$, et al. Reversible coronary microvascular dysfunction: A common pathogenetic mechanism in apical ballooning or tako-tsubo syndrome. Eur Heart J 2010; 31: 13191327.

8. Crea F, Camici PG, Noel Bairey Merz C. Coronary microvascular dysfunction: An update. Eur Heart J 2014; 35: 1101-1111.

9. Vitale C, Rosano GMC, Kaski JC. Role of coronary microvascular dysfunction in takotsubo cardiomyopathy. Circ J 2016; 80: 299-305.

10. Pelliccia F, Kaski JC, Crea F, Camici PG. Pathophysiology of takotsubo syndrome. Circulation 2017; 135: 2426-2441.

11. Pepine CJ, Ferdinand KC, Shaw LJ, Light-McGroary KA, Shah RU, Gulati M, et al. Emergence of nonobstructive coronary artery disease: A woman's problem and need for change in definition on angiography. J Am Coll Cardiol 2015; 66: 1918-1933.

12. Pasupathy S, Tavella R, Beltrame JF. Myocardial infarction with nonobstuctive coronary arteries (MINOCA): The past, present, and future management. Circulation 2017; 135: 1490-1493.

13. Brigden $\mathrm{W}$. Uncommon myocardial disease: The non-coronary cardiomyopathies. Lancet 1957; ii: 1179-1184 \& 1243-1249.

14. Goodwin JF, Gordon H, Hollman A, Bishop MB. Clinical aspect of cardiomyopathy. Br Med J 1961; 1: 69-79.

15. Goodwin JF. The frontiers of cardiomyopathy. Br Heart J 1982; 48: $1-18$.

16. Report of the WHO/ISFC task force on the definition and classification of cardiomyopathies. Br Heart J 1980; 44: 672-673.

17. Report of the $1995 \mathrm{WHO} / \mathrm{ISFC}$ task force on the definition and classification of cardiomyopathies. Circulation 1996; 93: 841-842.

18. Maron BJ, Towbin JA, Thiene G, Antzelevitch C, Corrado D, Arnett D, et al. Contemporary definition and classification of the cardiomyopathies: An American Heart Association Scientific Statement from the Council on Clinical Cardiology, Heart Failure and Transplantation Committee: Quality of Care and Outcome Research and Functional Genomics and Translational Biology Interdisciplinary Working Groups; and Council on Epidemiology and Prevention. Circulation 2006; 113: 1807-1816.

19. Elliott P, Andersson B, Arbustini E, Bilinska Z, Cecchi F, Charron P, et al. Classification of the cardiomyopathies: A position statement from the European Society of Cardiology Working Group on Myocardial and Pericardial Diseases. Eur Heart J 2008; 29: 270-276. 